Nixon, H. L. \& Harrison, B. D. (1959). J. gen. Microbiol. 21, 582-590

\title{
Electron Microscopic Evidence on the Structure of the Particles of Tobacco Rattle Virus
}

\author{
By H. L. NIXON AND B. D. HARRISON \\ Rothamsted Experimental Station, Harpenden, Hertfordshire
}

SUMMARY: The structure of tobacco rattle virus was studied by examining with the electron microscope: (1) shadow-cast mounts of particles partly degraded with alkali, sodium dodecyl sulphate or phenol; (2) unshadowed mounts on thin carbon film of particles treated with solutions of lanthanum nitrate, uranyl acetate, osmium tetroxide, phosphomolybdic acid or phosphotungstic acid.

The particles were tubular, with a central hole of approximately $4 \mathrm{~m} \mu$ diameter and an outside diameter which varied from 17 to $25 \mathrm{~m} \mu$ according to treatment. Next to the central hole, which could be filled with lanthanum nitrate or with uranyl acetate, was a region 1-1.5 $\mathrm{m} \mu$ thick, which stained heavily with osmium tetroxide, phosphomolybdic and phosphotungstic acids. The rest of the particle stained lightly with uranyl acetate, phosphomolybdic and phosphotungstic acids, and showed transverse bands $2.5 \mathrm{~m} \mu$ apart. It is suggested that these bands may represent a helical structure similar to that of tobacco mosaic virus, which tobacco rattle virus resembles in many respects.

Some properties of tobacco rattle virus have already been reported (Harrison $\&$ Nixon, 1959) and we now describe the structure of the particles as revealed by electron microscopy.

\section{METHODS}

The preparations of tobacco rattle virus used were made as already described (Harrison \& Nixon, 1959). For shadow-cast mounts the suspensions were usually mounted as gross drops on copper grids bearing collodion films. These were then shadowed with platinum in a modified commercial evaporating plant, using a pumping time of at least $2 \mathrm{hr}$. to minimize the grain size of the deposit. About 0.8-1.0 $\mathrm{m} \mu$ of platinum was usually deposited on the grids, which were placed $6-8 \mathrm{~cm}$. from the apex of a V-shaped tungsten filament made from two strands of $0.5 \mathrm{~mm}$. wire twisted together. Stained particles were mounted, usually as gross drops, on carbon films made by direct stripping from glass or freshly cleaved muscovite mica, and picked up on 4- or 7-hole platinum disks. Sometimes the suspensions were sprayed on to the mounts with the 'aerograph' air brush used for spraying suspensions in particle counting work (Nixon \& Fisher, 1958).

The following reagents were used as stains:

Lanthanum nitrate: $2 \%(\mathrm{w} / \mathrm{v})$ in water; $\mathrm{pH}$ c. 4.0 .

Osmium tetroxide: $2 \%(\mathrm{w} / \mathrm{v})$ in water; $\mathrm{pH}$ c. $5 \cdot \mathbf{0}$.

Phosphotungstic acid: $\mathrm{P}_{2} \mathrm{O}_{5} .24 \mathrm{WO}_{3} . x \mathrm{H}_{2} \mathrm{O} 0 \cdot 01-5 \cdot 0 \%(\mathrm{w} / \mathrm{v})$ in water; $2 \%$ solution was $\mathrm{pH} 2.3$.

Phosphomolybdic acid: $\mathrm{P}_{2} \mathrm{O}_{5} \cdot 24 \mathrm{MoO}_{3} . x \mathrm{H}_{2} \mathrm{O} 0 \cdot 01-5 \cdot 0 \%(\mathrm{w} / \mathrm{v})$ in water; $2 \%$ solution was $\mathrm{pH} 2 \cdot 0$.

Uranyl acetate: $2 \%(w / v)$ in water; $\mathrm{pH}$ c. $4 \cdot 2$. 
Phosphotungstic and phosphomolybdic acids were also used as : $1 \%(w / v)$ solutions adjusted to $\mathrm{pH} 6.5$ with $\mathrm{NaOH}$ (Brenner \& Horne, 1959). All these 'stains' except osmium tetroxide contain metals which give insoluble phosphates, and it was therefore necessary to free the virus suspensions from phosphate by dialysis against water or $0 \cdot 1 \mathrm{M}$-ammonium acetate solution when, as often happened, a phosphate buffer had been used as the final suspending fluid during virus purification. For the staining treatments $0 \cdot 1-0.5 \mathrm{mg}$. virus in $0 \cdot 1-0.5 \mathrm{ml}$. was pipetted into a centrifuge tube and stain added in excess (1-4 ml.). After shaking, the tubes were allowed to stand for about $1 \mathrm{hr}$. before centrifuging to pack the virus, which was invariably precipitated by the treatment. The pellets were resuspended in distilled water or $0.1 \mathrm{Mm}$ ammonium acetate and appropriately diluted for mounting as already described. Residual ammonium acetate, when present, was volatilized by gently heating the mount on a molybdenum strip in the evaporating plant before examination in the microscope. Attempts to evaporate the ammonium acetate with the electron beam in the microscope invariably broke the films.

Enzyme treatments. Virus solutions were incubated for $1 \mathrm{hr}$. at $37^{\circ}$ in $\mathrm{M} / 15$ phosphate buffer (pH 7.0) containing either crystallized trypsin (Armour Pharmaceutical Co.) at $1 \mathrm{mg} . / \mathrm{l}$., crude trypsin at $500 \mathrm{mg}$./l., or crystallized ribonuclease (Armour Pharmaceutical Co.) at $1 \mathrm{mg} . / 1$.

Electron microscopy. All the preparations were examined in a Siemens Elmiskop I electron microscope, with a $50 \mu$ objective aperture and fine focus condenser. Normally the microscope was operated at $80 \mathrm{kV}$, but $60 \mathrm{kV}$ was used when maximum contrast was necessary. Shadowed preparations were usually photographed at $\times 20,000$ and stained ones at $\times 80,000$; with stained ones, three or more photographs were usually taken in a through focus series, and the best photograph selected for further photographic enlargement. Measurements of the structures described below were made from prints at final magnifications of $\times 150,000-500,000$; the microscope was calibrated by the two-stage procedure recommended by the makers, with a $70 \mu$ hole in a platinum disk, measured with a calibrated light microscope, as a primary standard.

\section{RESULTS}

\section{Shadowed particles of purified virus}

Particle lengths of tobacco rattle virus have already been discussed (Harrison $\&$ Nixon, 1959) and will not be further considered here. The particles in shadowed mounts seemed to be $c .25 \mathrm{~m} \mu$ wide when they lay with their long axes in the direction of shadowing. Particle widths will be further considered below in the section on stained particles. The ends of a few particles appeared collapsed, and this suggestion of a tubular structure was supported by the ringlike appearance of very short particles which had dried end-on to the supporting film (Pl. 1, fig. 1). These rings had a central hole about $4 \mathrm{~m} \mu$ in diameter, and were rather similar to the end-on views of to bacco mosaic virus fragments obtained by Williams (1952) after ultrasonic treatment. Williams, however, obtained some tobacco mosaic virus rings with a hexagonal'outline 
when the mounts had been made from freshly-treated virus preparations. We have not observed these with tobacco rattle virus, and our failure to do so can hardly be due to lack of resolving power, for tobacco rattle virus is larger than tobacco mosaic virus and our instrument normally has a resolving power of $c .1 \mathrm{~m} \mu$.

Partial degradation followed by examination of shadowed material. Alkali and sodium dodecyl sulphate partly degrade tobacco mosaic virus (Sreenivasaya \& Pirie, 1938; Schramm, 1947; Hart, 1955), and these treatments were therefore applied to tobacco rattle virus to see whether they would produce fragments which might give information about the structure of the particles. The most useful alkali treatment was to heat virus suspension in $0.05 \mathrm{M}$ sodium carbonate + borate buffer $(\mathrm{pH}$ 10.2). Virus heated under these conditions to $40^{\circ}$ for $12 \mathrm{~min}$. retained some infectivity, but not after heating to $45^{\circ}$ for $12 \mathrm{~min}$. Of the few particles found with the electron microscope in such preparations most were normal in appearance, but occasionally one was found with a structure suggesting that the outer part of the particle had been partly stripped from a core, which appeared to be about $15 \mathrm{~m} \mu$ in diameter (Pl. 1, fig. 3). Rings were much more numerous in the treated virus preparations than in the untreated ones; they had holes about $6 \mathrm{~m} \mu$ in diameter (Pl. 1, fig. 4) larger than those in untreated preparations, but smaller than the core of the particle shown in PI. 1, fig. 3, and referred to above. Shadow lengths suggest that these rings with large holes may be thinner than those in untreated preparations (Pl. 1, fig. 1), but it is difficult to be certain of this because preparations of partly-degraded particles contain much low-molecular weight material which obstructs observations and measurements. Very similar pictures were obtained after treatment with $0.02 \%(\mathrm{w} / \mathrm{v})$ sodium dodecyl sulphate at $\mathrm{pH} 7 \cdot 0$ for about $1 \mathrm{~min}$. at $60^{\circ}$, or for about $5 \mathrm{~min}$. at $50^{\circ}$ (Pl. 1, fig. 2). Such preparations had lost all infectivity, and most particles remaining after treatment appeared normal. Some of the rings from alkali and from sodium dodecyl sulphate treatments appeared to have one or more angular corners, in contrast to the very well-defined circular rings in Pl. 1, fig. 1. Perhaps the true cross-section is in fact hexagonal, obscured in Pl. 1, fig. 1 by a coating of some substance which is removed by the alkali and sodium dodecyl sulphate treatments. Alternatively the angular outline might have been produced by the alkali and sodium dodecyl sulphate treatments removing material formerly an integral part of the particles, or the angular rings may have been formed by small degradation products re-aggregated in the manner suggested by Harrington \& Schachman (1956) for tobacco mosaic virus. Rings in stained preparations appeared to be circular, even at very high magnifications (Pl. 4).

Particles were also degraded by treating them with aqueous phenol. Various concentrations were tried, but most information came from pictures of a virus suspension in $0.1 \%(\mathrm{w} / \mathrm{v})$ phenol allowed to react at room temperature for $24 \mathrm{hr}$. Plate 2, fig. 5, illustrates such a preparation and shows that the ends of many of the particles had disintegrated, revealing the tubular structure very well. It is difficult to measure the diameter of the central hole accurately, as the particles tend to collapse inwards, but estimates suggest that it is about 
$6 \mathrm{~m} \mu$ in diameter. A few particles had thread-like material projecting from them; one is shown in the upper right corner of Pl. 2, fig. 5. This thread-like substance may well be the nucleic acid; treatment with more concentrated phenol has been used to isolate infective nucleic acid preparations from tobacco mosaic virus (Gierer \& Schramm, 1956). The appearance of the phenol-treated virus varied characteristically, both between duplicate mounts and in different regions of the same mount. In some preparations all gradations from apparently undamaged particles to completely disrupted ones were found in a width of a few hundred microns on the mount. This variability may have been caused by local high concentrations of phenol on those parts of the grid to which the last traces of liquid receded as the drop dried; in these regions the attack would be more severe, for the water would evaporate preferentially. The particles might thus have been attacked as they lay on the mount, the fragments remaining nearby as the liquid dried.

\section{Stained preparations}

Stained preparations were usually examined as gross drop mounts on thin carbon films, and in the following descriptions this technique can be assumed to have been used unless another is specifically mentioned. The staining treatments caused considerable aggregation; osmium-stained preparations retained about half their infectivity, but the other reagents, probably because of their acidity, destroyed almost all of the infectivity. Stained preparations usually gave good contrast in the electron microscope, permitting accurate focusing at $\times 80,000$, but it was sometimes necessary to work at $60 \mathrm{kV}$. and to use a high contrast developer to obtain images which could be printed satisfactorily. Plates 2-4 record typical results and show that two main types of image were produced. Osmium tetroxide, phosphotungstic acid and phosphomolybdic acid gave a densely stained central core 6-7 $\mathrm{m} \mu$ wide, that is, about one-third of the width of the particle, whereas with uranyl acetate and with lanthanum nitrate the core was less dense and only 4-4.5 $\mathrm{m} \mu$ wide. The outside edges and the boundaries of the central cores were clearly defined, allowing the total and core widths to be measured (Table 1 ). In unstained control preparations, the central core could only just be seen (Pl. 2, fig. 6), and this is probably the reason for the high error for the estimate of the core width in unstained particles. After treatment with neutralized phosphotungstate or phosphomolybdate followed by spraying on to mounts (Brenner \& Horne, 1959), many particles showed visible changes in width along their lengths; no useful estimate of particle width was possible on these specimens. Differences in total width of the same order are also found with the various stains (Table 1).

Rings were common in the phosphotungstic acid-stained preparations, and the central dark area in them corresponded in size to that of the central band in similarly treated rods. It was also approximately equal to the size of the central hole in the rings from the virus preparations treated with alkali or sodium dodecyl sulphate. Sometimes phosphotungstic acid-stained particles showed a slightly different picture, with a lightly stained central region having narrow but densely stained edges (Pl. 4, fig. 13). We think that this 
indicates that the stain had been partially removed, for it can easily be washed out either by dialysis or by repeated sedimentation and resuspension in distilled water. Particles which have been stained with phosphotungstic acid and then washed free from stain in this way can be re-stained with phosphotungstic acid, but less intensely than before. They can also be re-stained with uranyl acetate, when they show the narrow central band characteristic of that stain, so that deposition and subsequent removal of phosphotungstic acid seems not to remove material other than the stain itself from the centres of Table 1. Estimates of total width and core width of tobacco rattle virus
particles treated with various agents

\begin{tabular}{|c|c|c|}
\hline Treatment & $\begin{array}{l}\text { Mean total width } \\
(\mathrm{m} \mu)\end{array}$ & $\begin{array}{l}\text { Mean core width } \\
(\mathrm{m} \mu)\end{array}$ \\
\hline $\begin{array}{l}\text { Unstained } \\
2 \%(w / v) \text { Lanthanum nitrate; pH } c .4 \cdot 0 \\
1 \%(w / v) \text { Osmium tetroxide; pH 5.5 } \\
2 \%(w / v) \text { Phosphomolybdic acid; pH } 2 \cdot 0 \\
2 \%(w / v) \text { Phosphotungstic acid; pH } 3 \cdot 0 \\
2 \%(w / v) \text { Uranyl acetate; pH } 4.0\end{array}$ & $\begin{array}{l}21 \cdot 84 \pm 0 \cdot 31 \\
22 \cdot 65 \pm 0 \cdot 10 \\
22 \cdot 36 \pm 0 \cdot 71 \\
17 \cdot 16 \pm 0 \cdot 064 \\
19 \cdot 99 \pm 0 \cdot 22 \\
19 \cdot 94 \pm 0 \cdot 33\end{array}$ & $\begin{array}{l}4 \cdot 18 \pm 1 \cdot 00 \\
3 \cdot 99 \pm 0 \cdot 10 \\
5 \cdot 94 \pm 0 \cdot 055 \\
6 \cdot 98 \pm 0 \cdot 036 \\
5 \cdot 96 \pm 0 \cdot 26 \\
4 \cdot 39 \pm 0 \cdot 25\end{array}$ \\
\hline
\end{tabular}

the particles. Further evidence for this conclusion is provided by the ultraviolet absorption spectrum of such stained and washed particles which closely resembled that of untreated virus particles. Raising the concentration of phosphotungstic or phosphomolybdic acids or of uranyl acetate to $5 \%$ had little effect on the intensity of staining; with concentrations of stain less than $2 \%(w / v)$, the staining became progressively weaker, but even with $0.01 \%$ $(\mathrm{w} / \mathrm{v})$ phosphotungstic acid there was still some staining. The $\mathrm{pH}$ values given in Table 1 are those for aqueous solutions of the reagents at the concentrations stated. Phosphotungstic and phosphomolybdic acids stained less intensely at

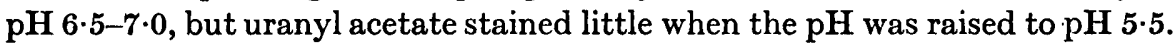

Enzyme treatments. Incubation with trypsin under the conditions used for these experiments had little effect upon infectivity. Ribonuclease at $1 \mathrm{mg}$./l. strongly inhibited infection, and even at $0.1 \mathrm{mg}$./l. it decreased lesion numbers to about a quarter of the control values. However, ribonuclease did not destroy infectivity in vitro, because infectivity was restored by diluting the mixtures. Also, samples incubated for $4 \mathrm{hr}$. at $37^{\circ}$ with ribonuclease $(0 \cdot 1 \mathrm{mg} . / 1$. were as infective as samples to which the ribonuclease was added immediately before inoculation. Particles incubated with trypsin or ribonuclease and then stained with phosphotungstic acid were indistinguishable from similarly stained ones which had not been treated with the enzymes; incubation with ribonuclease had no effect upon the appearance of particles subsequently stained with uranyl acetate.

Transverse bands. Particles stained with phosphomolybdic acid at $\mathrm{pH} \mathrm{3.0}$ appeared similar to those treated with phosphotungstic acid, except that they showed a regular array of transverse bands (Pl. 3, fig. 9). After this had been found, careful inspection revealed traces of a similar structure in some pictures of phosphotungstic acid-stained virus particles. Particles incubated 
with trypsin before staining with uranyl acetate also showed transverse bands (Pl. 3, fig. 11). These structures were observed on a number of occasions, and when seen they could usually be detected on all the particles in a field and always in several plates of a through-focus series. The dark bands cross the particles and were separated by lighter areas which are approximately equal to them in width. In some pictures there was a suggestion that the dark bands were not quite at right angles to the long axes of the particles, but it is difficult to be certain of this because often they could not be traced across the heavily stained centres of the particles. Estimates of the spacing of the dark lines, obtained by measuring tracings of high magnification high-contrast images, are given in Table 2 . If the dark and light bands are assumed to be of equal width, each must be $1 \cdot 2-1 \cdot 3 \mathrm{~m} \mu$ wide.

Table 2. Spacing of the transverse bands on stained particles of tobacco rattle virus

\begin{tabular}{lcc}
\multicolumn{1}{c}{ Stain } & $\begin{array}{c}\text { Spacing } \\
(\mathrm{m} \mu)\end{array}$ & $\begin{array}{c}\text { Number } \\
\text { measured }\end{array}$ \\
Phosphoinolybdic acid & $2 \cdot 59$ & 120 \\
Phosphotungstic acid & $2 \cdot 44$ & 53 \\
Uranyl acetate & $2 \cdot 50$ & 192 \\
Mean & $2 \cdot 52$ & 365 (total)
\end{tabular}

\section{DISCUSSION}

The tubular nature of tobacco rattle virus particles is clearly evident from the shadow-cast pictures of partly-degraded material (Pls. 1, 2). These plates also show how closely the tobacco rattle virus particle resembles tobacco mosaic virus in its general appearance; we have already drawn attention to the resemblances in some other properties (Harrison \& Nixon, 1959). The pictures suggest that the central hole may be about $4 \mathrm{~m} \mu$ in diameter, as in shadow-cast preparations of purified virus (Pl. 1, fig. 1) or rather larger (about $6 \mathrm{~m} \mu$ ) in particles treated with alkali, sodium dodecyl sulphate or phenol. The projecting core of the particle in Pl. 1, fig. 3, is about $15 \mathrm{~m} \mu$ in diameter; but whereas rings with $6 \mathrm{~m} \mu$ holes are abundant, particles with $15 \mathrm{~m} \mu$ cores are rare, and their structural significance, if any, is unknown. The diameter of the holes in rings, and the width of the central cores in stained particles, also fall into two groups. The simplest explanation, namely that particles stained with osmium tetroxide, phosphotungstic acid or phosphomolybdic acid all have material removed from their centres by the staining treatment, and that the resulting cavity is then filled loosely with stain, cannot be true; for although it is possible to remove phosphotungstic and phosphomolybdic acids by dialysis, such particles then show a narrow core when restained with uranyl acetate. Moreover, particles stained with phosphotungstic acid and then dialysed free from stain still have a similar ultraviolet absorption spectrum to that of untreated virus preparations. And osmium tetroxide stained particles, which appear stained in a manner similar to those treated with phosphotungstic and phosphomolybdic acids, still retain 
considerable infectivity. The substance lining the central hole thus differs from the rest of the particle in staining heavily with osmium tetroxide, phosphotungstic acid or phosphomolybdic acid and also in being readily removed by phenol and other agents.

The results from examining stained and partially-degraded particles fit together very well, and it is reasonable to suppose that both reflect the structure of the intact particle. The diagram (Fig. 1) summarizes these observations. The great similarity in appearance and many other properties between tobacco rattle virus and tobacco mosaic virus makes it seem reasonable to suppose that the two particles have a similar internal structure. The internal structure of tobacco mosaic virus has been intensively studied by $\mathrm{X}$-ray diffraction, and the particle has been shown to consist of structurally equivalent protein subunits with a molecular weight of about 18,000 arranged in a helix about the long axis of the rod, the pitch of the helix being $2 \cdot 3 \mathrm{~m} \mu$ and the maximum diameter $18 \mathrm{~m} \mu$. The outside of the particle is grooved, so that the apparent width is decreased to $15 \mathrm{~m} \mu$ when particles pack closely together. Estimates of radial density indicate that the phosphate-sugar 'backbone' of the ribonucleic acid

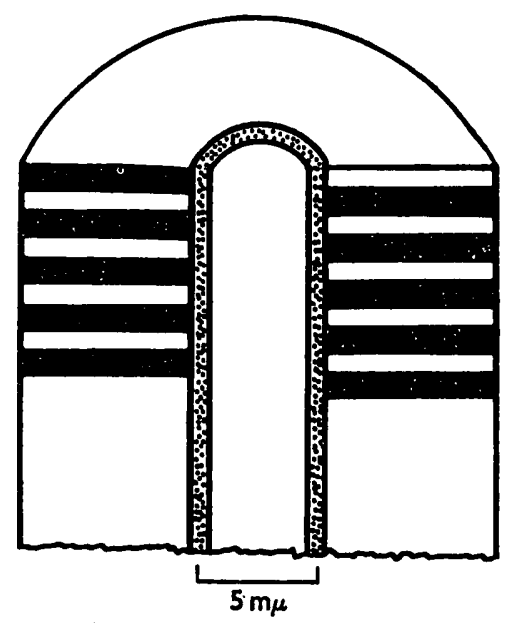

Fig. 1. Diagram to show the structure of the tobacco rattle virus particle as revealed by electron microscopy.

lies $4.0 \mathrm{~m} \mu$ distant from the centre of the rod (Holmes \& Franklin, 1958). Assuming that tobacco rattle virus has a similar structure to tobacco mosaic virus, but with slightly different dimensions, the transverse bands we have observed on rods may well represent the protein helix of that particle. Early attempts to stain tobacco mosaic virus in a similar manner invariably failed to show more than the central core first observed by Huxley (1957), and even this is not always visible, suggesting that perhaps it may only be seen on partly-degraded particles. However, we have now been able to stain tobacco mosaic virus with phosphomolybdic acid, and such preparations give pictures essentially similar to those of tobacco rattle virus shown here, although 
tobacco mosaic virus has less affinity for stain than tobacco rattle virus (Pl. 2, fig. 7). The work on stained tobacco mosaic virus will be described elsewhere.

Our experiments provide no direct evidence about the position of the nucleic acid within the tobacco rattle virus particles. However, they do suggest that the outer part of tobacco rattle virus must differ from the parts adjacent to the central hole. Further, the ready accessibility of these inner parts of the tobacco rattle virus particle to strains suggests that the nucleic acid is not here, for if it were it might be accessible to enzymic digestion, and the virus is resistant to both trypsin and ribonuclease in vitro. Another suggestion, which we consider to be more plausible, is that the nucleic acid is located in that part of the particle which we have been able to stain least, namely the region which lies immediately outside the part which lines the central hole. Perhaps this part of the particle has a low affinity for stain because it is the densest part, and it is interesting to observe that when the structure of tobacco mosaic virus is scaled up by the ratio of the total widths of tobacco rattle virus: tobacco mosaic virus, then the nucleic acid would occupy a position $5 \mathrm{~m} \mu$ from the centre, which is, in fact, that part of the tobacco rattle virus particle which stains least.

We wish to acknowledge the assistance of Mr R. D. Woods.

\section{REFERENCES}

Brenner, S. \& Horne, R. W. (1959). A negative staining method for high resolution electron microscopy of viruses. Biochim. biophys. Acta, 34, 103.

Gierer, A. \& Schramm, G. (1956). Infectivity of ribonucleic acid from tobacco. mosaic virus. Nature, Lond. $177,702$.

Harrington, W. F. \& Schachman, H. K. (1956). Studies on the alkaline degradation of tobacco mosaic virus. I. Ultracentrifugal analysis. Arch. Biochem. Biophys. 65, 278.

Harrison, B. D. \& Nixon, H. L. (1959). Separation and properties of particles of tobacco rattle virus with different lengths. J. gen. Microbiol. 21, 569.

HART, R. G. (1955). Electron-microscopic evidence for the localization of ribonucleic acid in the particles of tobacco mosaic virus. Proc. nat. Acad. Sci., Wash. 41, 261.

Holmes, K. C. \& Franklin, R. E. (1958). The radial density distribution in some strains of tobacco mosaic virus. Virology, 6, 328.

HuXLEY, H. E. (1957). Some observations on the structure of tobacco mosaic virus: Proc. int. Conf. Electron Microscopy, Stockholm, 1956, p. 260.

Nixon, H. L. \& Fisher, H. L. (1958). An improved spray droplet technique for quantitative electron microscopy. Brit. J. appl. Phys. 9, 68.

Schramm, G. (1947). UUber die Spaltung des Tabakmosaikvirus und die - Wiedervereinigung der Spaltstücke zu höhermolekularen .Proteỉnen. I. Die Spaltungsreaktion. Z. Naturf. $2 b, 112$.

Sreenivasaya, M. \& Pirie, N. W. (1938). The disintegration of tobacco mosaic virus preparations with sodium dodecyl sulphate. Biochem. J. 32, 1707.

Williams, R. C. (1952). High-resolution electron microscopy of the particles of tobacco mosaic virus. Biochim. biophys. Acta, 8, 227. 


\section{EXPLANATION OF PLATES}

\section{Plate 1}

Fig. 1. Tobacco rattle virus particles from a purified preparation. Gross-drop mount on collodion, shadowed with platinum. Two short fragments of rod lie end-on and show the central hole, approximately $4 \mathrm{~m} \mu$ in diameter. $\times 150,000$.

Fig. 2. Particles from a preparation treated with $0.02 \%(w / v)$ sodium dodecyl sulphate at pH 7.0 for 30 sec. at $60^{\circ}$. Gross-drop mount on collodion shadowed with platinum. Two fragments of rod lie end-on. They have an angular outline, with a central hole approximately $6 \mathrm{~m} \mu$ in diameter. $\times 150,000$.

Fig. 3. Particles from a preparation heated in $0 \cdot 1 \mathrm{M}$-sodium borate + carbonate buffer (pH 10.3) for $10 \mathrm{~min}$. at $45^{\circ}$. Gross-drop mount on collodion, shadowed with platinum. Towards the lower right one particle shows a projecting core $15 \mathrm{~m} \mu$ in diameter. $\times 150,000$.

Fig. 4. Particles from a preparation heated with $0 \cdot 1 \mathrm{M}$-sodium borate + carbonate buffer (pH 10.3) for 5 min. at $46^{\circ}$. Gross-drop mount on collodion film, shadowed with platinum. Two short fragments lie end-on. They have an angular outline and a central hole approximately $6 \mathrm{~m} \mu$ in diameter. $\times 150,000$.

\section{Plate 2}

Fig. 5. Particles from a tobacco rattle virus preparation treated for $24 \mathrm{hr}$. with $0 \cdot 1 \%$ (w/v) phenol at room temperature. Gross-drop mount on collodion film, shadowed with platinum. Many of the rods have damaged ends, showing the tubular structure. In the upper right corner, thread-like material, possibly nucleic acid, can be seen. $\times 150,000$.

Fig. 6. Tobacco rattle virus particles from a purified preparation mounted on a carbon film. The central hole is just visible as a dark line on some particles. $\times 400,000$.

Fig. 7. Particles from a mixed preparation of tobacco rattle virus and tobacco mosaic virus, stained with $2 \%(\mathrm{w} / \mathrm{v})$ phosphotungstic acid (pH 3.0). The relative widths of the two viruses and their different affinities for stain are clearly seen. $\times 400,000$.

\section{Plate 3}

Fig. 8. Tobacco rattle virus particles stained with $5 \%$ lanthanum nitrate at pH 4.0. Carbon film, gross-drop mount. The particles are strongly outlined and the central hole is heavily stained. $\times 400,000$.

Fig. 9. Tobacco rattle virus particles stained with $2 \%(\mathrm{w} / \mathrm{v})$ phosphomolybdic acid (pH 2.0). Gross-drop mount on carbon film. The particles have shrunk to a width of about $17 \mathrm{~m} \mu$, and both central hole and transverse banding are visible. $\times \mathbf{4 0 0 , 0 0 0}$.

Fig. 10. Tobacco rattle virus particles stained with $2 \%(\mathrm{w} / \mathrm{v})$ uranyl acetate (pH 4.0). Gross-drop mount on carbon film. The central hole and transverse banding are visible. $\times 400,000$.

Fig. 11. A similar preparation to fig. 10, but stained after incubation with trypsin. The transverse bands are now more densely stained than the central hole. $\times 400,000$.

\section{Plate 4.}

Fig. 12. Tobacco rattle virus particles stained with $2 \%(w / v)$ phosphotungstic acid (pH 3.0). The wide central region is heavily stained, but no transverse banding is visible. $\times 400,000$.

Fig. 13. Tobacco rattle virus particles, stained with $2 \%(w / v)$ phosphotungstic acid (pH 6.0). Gross-drop mount on carbon film. The stain has been partially removed from the particles during washing, but the central region is still clearly outlined. $\times 400,000$.

Fig. 14. Tobacco rattle virus particles, stained with $2 \%(w / v)$ phosphotungstic acid (pH 7.0) and mounted on carbon film by spraying without washing. The particles show typical staining like those in Pl. 4, fig. 12, and several fragments are seen end-on. There is some indication that the outside surface is irregular. $\times 400,000$.

Fig. 15. Tobacco rattle virus particles, stained with $1 \%(w / v)$ osmium tetroxide at pH 5.5. The staining pattern resembles that shown in Pl. 4, fig. 12, and no transverse banding visible. Particles treated in this way retain considerable infectivity. $\times \mathbf{4 0 0 , 0 0 0}$. 
Journal of General Microbiology, Vol. 21, No. 3
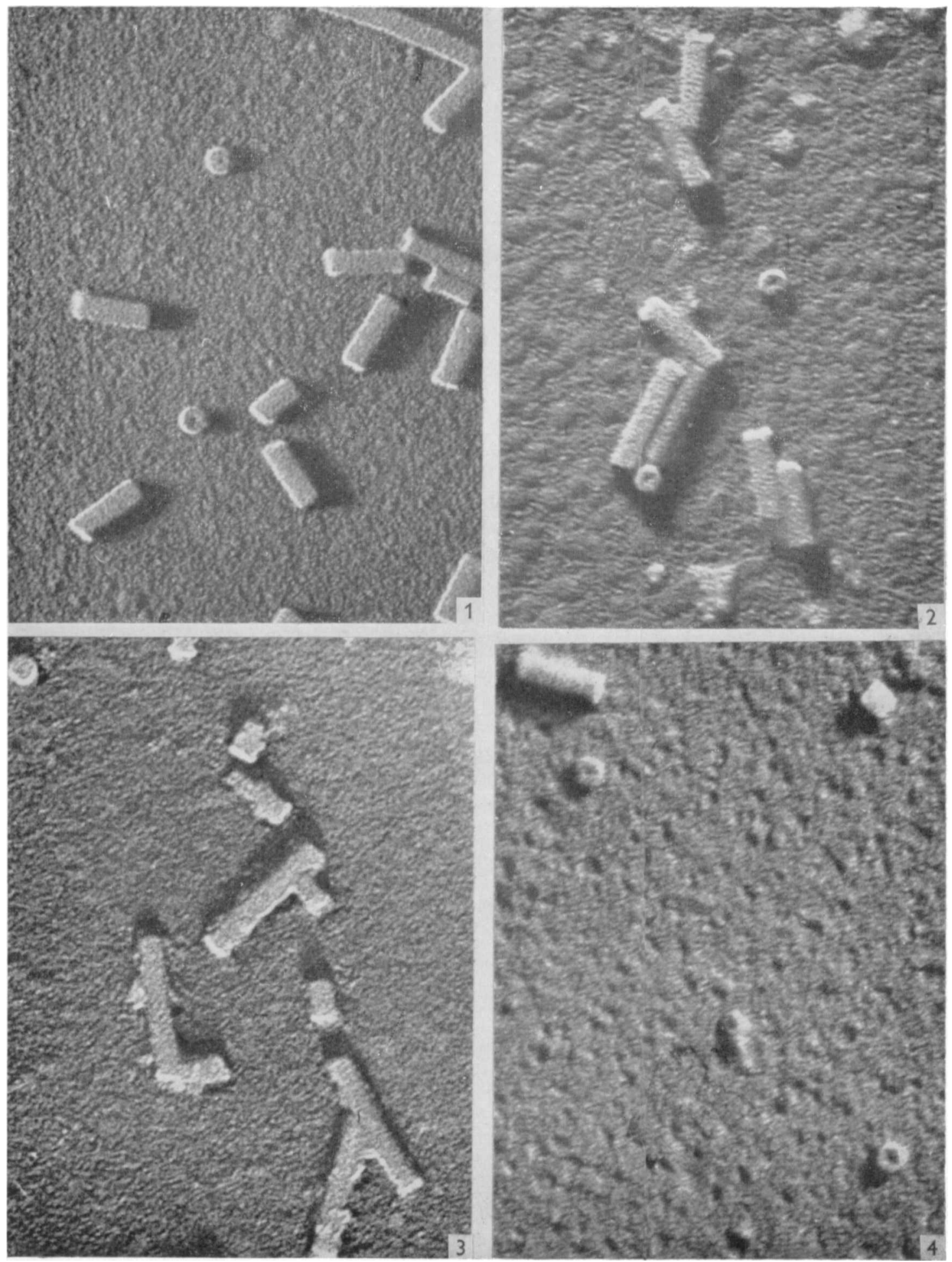

H. L. Nixon \& B. D. Harrison-Structure of tobacco rattle virus. Plate 1 


\section{Journal of General Microbiology, Vol. 21, No. 3}
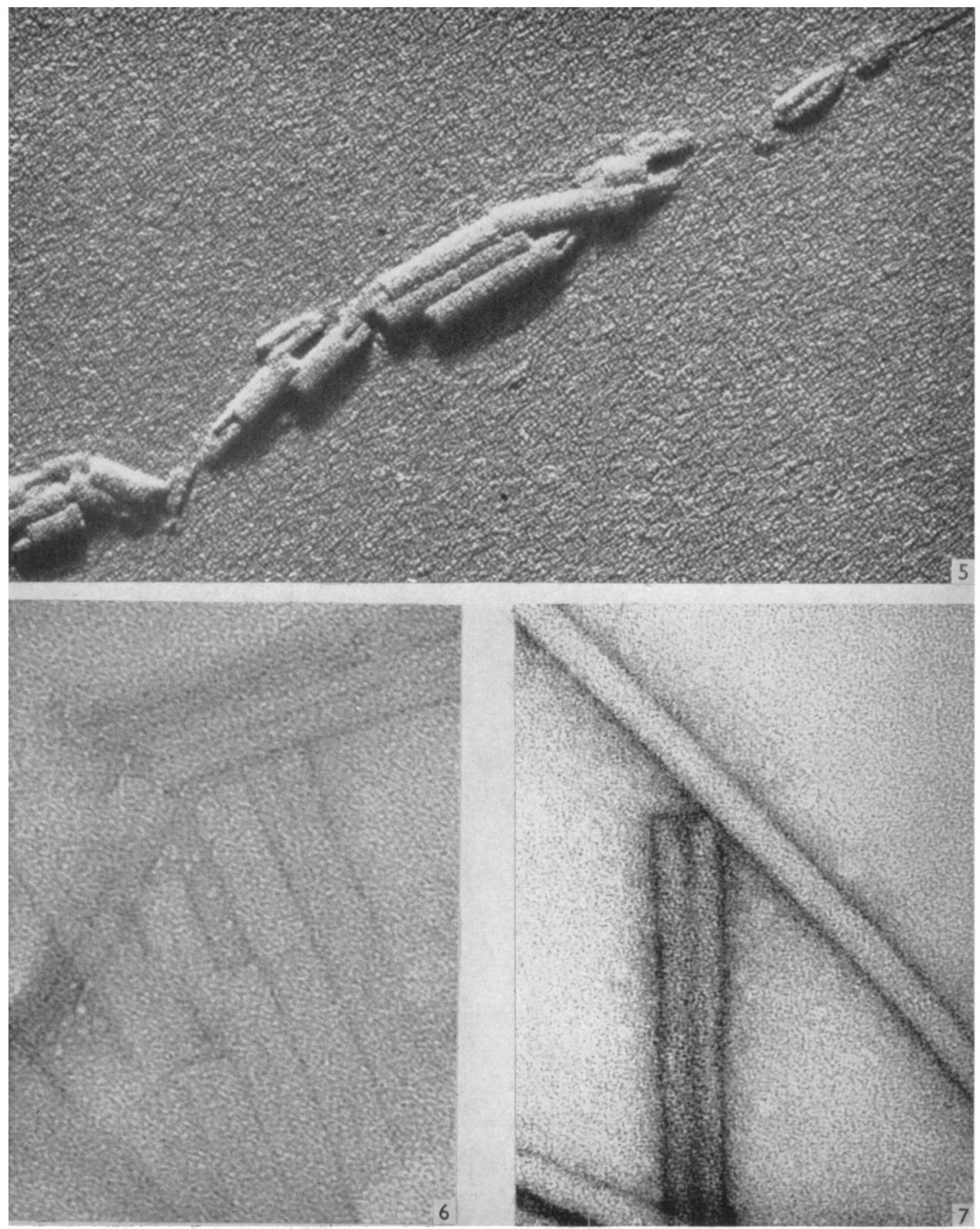

H. L. Nixon \& B. D. Harrison-Structure of tobacco rattle virus. Pla'te 2 
Journal of General Microbiology, Vol. 21, No. 3
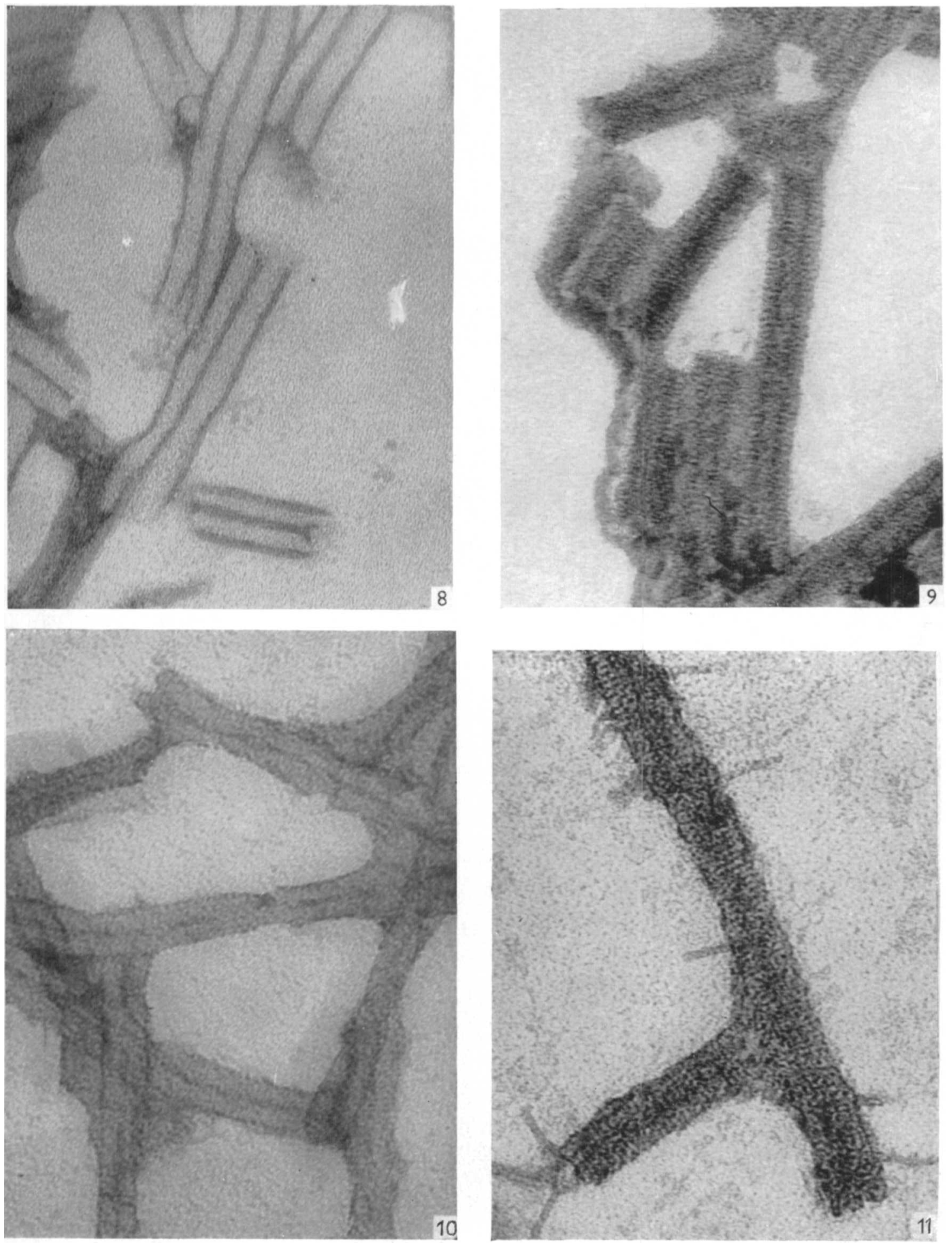

H. L. Nixon \& B. D. Harrison-Structure. of tobacco ratile virus, Plate 3 
Journal of General Microbiology, Vol. 21, No. 3
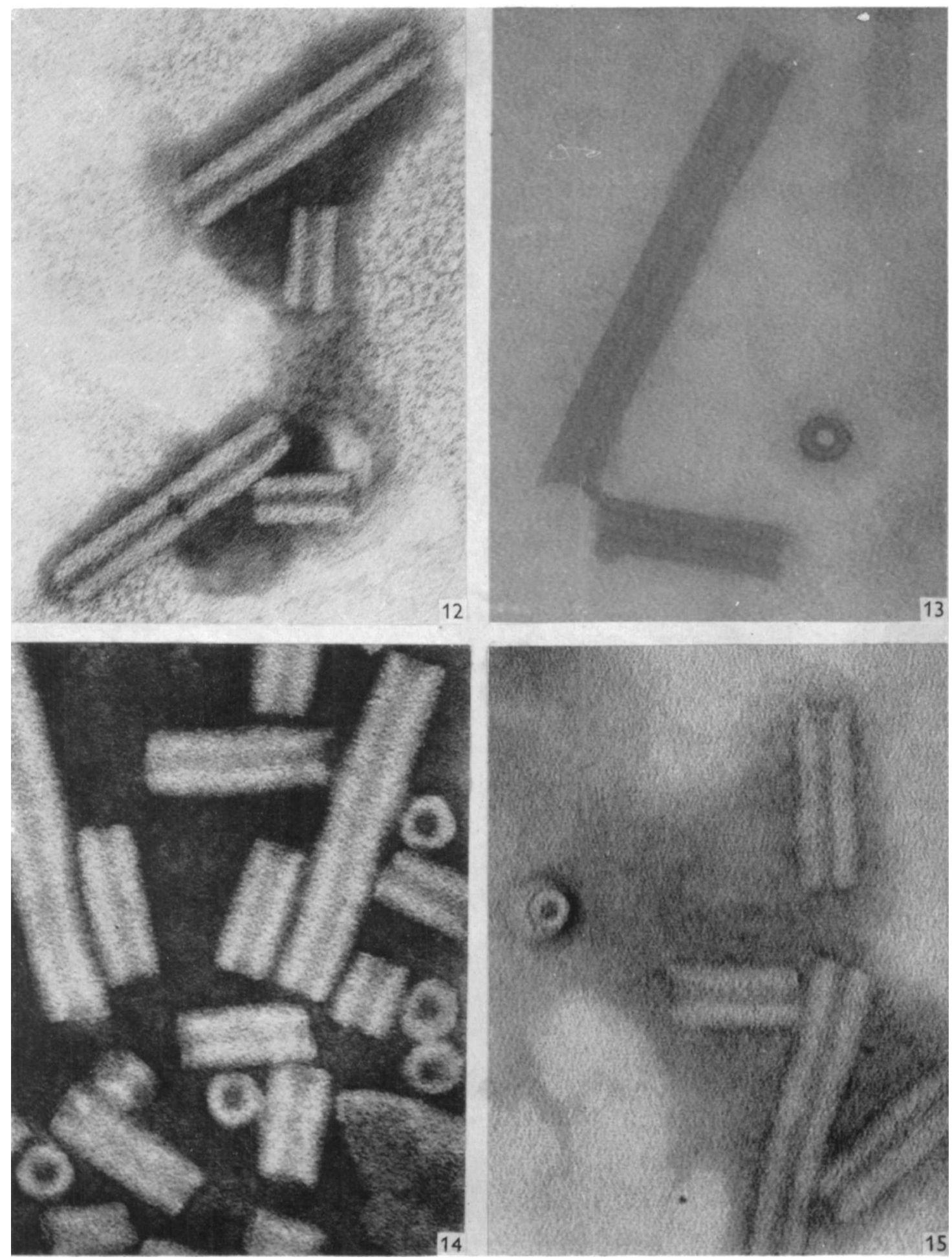

H. L. Nixon \& B. D. Harrison-Strructure of tobacco rattle virus, Piate 4 